\title{
Rechtsprechung
}

\section{Urheberrechtliches Änderungsverbot versus Projekt Stuttgart 21}

OLG Stuttgart, Urteil vom 6. Oktober 2010 - 4 U 106/10

Das urheberrechtliche Änderungsverbot steht dem Umbau des Stuttgarter Hauptbahnhofs im Rahmen des Projekts Stuttgart 21 nicht entgegen, denn im Rahmen der vorzunehmenden Interessenabwägung sind im konkreten Fall die Eigentümerinteressen schwerwiegender als die Urheberinteressen.

In die Abwägungsentscheidung ist nur die konkrete Planung einzustellen. Die von der Beklagten geltend gemachten städtebaulichen Belange sind für die Interessenabwägung nicht relevant.

\section{Tenor}

1. Die Berufung des Klägers gegen das Urteil des Landgerichts Stuttgart vom 20. Mai 2010 (17 O 42/10) wird zurückgewiesen.

2. Der Kläger trägt die Kosten des Berufungsverfahrens.

3. Das Urteil ist gegen Sicherheitsleistung in Höhe von $120 \%$ des jeweils zu vollstreckenden Betrages vorläufig vollstreckbar.

4. Die Revision wird nicht zugelassen.

Streitwert des Berufungsverfahrens: 1.000.000,00 EUR.

\section{Gründe}

\section{A. Tatbestand}

- Der Kläger will erreichen, dass es die Beklagten unterlassen, im Rahmen des Projekts Stuttgart 21 die Seitenflügel des Stuttgarter Hauptbahnhofs und die Treppenanlage in der Großen Schalterhalle abzureißen. Hinsichtlich des im August/September 2010 abgerissenen Nordflügels begehrt er den Wiederaufbau.

\section{Sachverhalt und Vortrag in erster Instanz}

Der Kläger ist ein Erbe des Architekten Paul Bonatz (geboren am 6. Dezember 1877, gestorben am 20. Dezember 1956), der den Stuttgarter Hauptbahnhof geplant und dessen Bauausführung geleitet hat.

Den Architektenwettbewerb für das Empfangsgebäude des damals neuen Hauptbahnhofs an der Schillerstraße gewann das Architekturbüro Bonatz und Scholer am 20. Juni 1911 mit dem Entwurf "umbilicus sueviae“ (= der Nabel Schwabens), der Architektenvertrag wurde am 14./30. Mai 1913 abgeschlossen (...). Paul Bonatz war schwerpunktmäßig für den Entwurf, der 1949 verstorbene Friedrich Eugen Scholer für Ausarbeitungen und technische Fragen zuständig. Der Bahnhof wurde in den Jah- ren 1914 bis 1928 errichtet, bedingt durch den ersten Weltkrieg kam es zu Bauverzögerungen. Nach erheblichen Zerstörungen im zweiten Weltkrieg erfolgte der Wiederaufbau ebenfalls unter Mitwirkung von Paul Bonatz. (...) Nach dem Tod von Paul Bonatz wurden weitere Umbauarbeiten vorgenommen. Die Treppe in der großen Schalterhalle wurde ersetzt, es wurden Rolltreppen angebracht und ein Durchbruch auf der Ebene der Schalterhalle zur Anbindung der unterirdischen Arnulf-KlettPassage vorgenommen (...).

Am 28. Februar 1997 hat die Beklagte Ziff. 1 unter Beteiligung der Stadt Stuttgart und des Landes Baden-Württemberg einen Architektenwettbewerb zum Umbau des Hauptbahnhofs ausgeschrieben, wobei unter anderem der Erhalt der Treppenkonstruktionen gefordert wurde und zur Frage eines Abrisses der Seitenflügel wie folgt ausgeführt wird (...):

„(...) Dem Bahnhofsgebäude werden bei allen Entwürfen des kooperativen Gutachterverfahrens entsprechend den Vorgaben einer modernen Verkehrsstation neue Nutzungen zugeführt. Die Funktionalität des Stuttgarter Hauptbahnhofs war eine wesentliche Vorgabe für den Architekten Paul Bonatz. Sie wird getragen von der großen und kleinen Schalterhalle, dem Mittelgang, dem ebenerdigen Nordausgang und der groBen Kopfbahnsteighalle. Diese Raumkonstruktionen mit ihren Treppenverbindungen sind zwingend zu erhalten.

Wie das Ergebnis des kooperativen Gutachtens zeigt, erscheint eine sinnvolle städtebauliche Weiterentwicklung der Kernstadt nur bei einem Abbruch der Seitenflügel möglich. Sollten diese städtebaulichen Vorgaben von den Planverfassern mitgetragen werden, so müssen die öffentlichen Interessen der Erhaltung des Kulturdenkmals Hauptbahnhof Stuttgart zu den öffentlichen Interessen einer funktionierenden Stadterweiterung mit einer angeschlossenen modernen Verkehrssituation gegeneinander abgewogen werden.

Denkmalpflegerisch ist der Erhalt der Flügelbauten zu fordern. Bei einer überzeugenden Darstellung und Darlegung der übergeordneten Gründe einer funktionierenden Stadterweiterung mit einer modernen Verkehrssituation wird es den Planverfassern freigestellt, die Flügelbauten abzubrechen. (...) 
Es ist anzustreben, die wesentlichen Teile des denkmalgeschützten Hauptbahnhofs und die sich aus den Anforderungen der Gegenwart ergebenen Architekturelemente zu einer neuen, baulich gestalterischen Einheit zu verbinden. (...)"

Der Kläger leitet daraus her, dass die Erhaltung der Seitenflügel gefordert worden sei.

Das Urheberrecht von Paul Bonatz wurde im Wettbewerb und im anschließenden Planfeststellungsverfahren nicht thematisiert. Der Kläger schließt daraus und aus den weiteren Abläufen im Wettbewerb und im Genehmigungsverfahren, dass es den Beklagten (und der Stadt Stuttgart) nur um eine städtebauliche Weiterentwicklung gehe und die Flügelbauten der geänderten Funktion nicht im Wege stünden - die Beklagten haben dies in Abrede gestellt. Die Beklagten haben vorgetragen, ihnen seien die ererbten Urheberrechte nicht bekannt gewesen.

Nach Preisgerichtssitzungen im April und Juni 1997 wurde am 4. November 1997 als Siegerentwurf der Vorschlag des damaligen Büros Ingenhoven, Overdiek, Kahlen und Partner (...) gekürt. Danach sollen die Seitenflügel und die Treppenanlage in der großen Schalterhalle abgerissen werden, das Bodenniveau der Kopfbahnsteighalle soll abgesenkt werden. Der Planfeststellungsantrag vom 30. Oktober 2001 und das anschließende Planfeststellungsverfahren des Eisenbahnbundesamts endeten mit dem Planfeststellungsbeschluss vom 28. Januar 2005, der am 28. Februar 2005 öffentlich bekannt gemacht wurde (...). Die im Planfeststellungsverfahren erhobenen Einwendungen des Klägers wurden zurückgewiesen (...). Nach einem sogenannten "Memorandum of Understanding“ am 19. Juli 2007 wurden die Finanzierungsverträge am 2. April 2009 unterzeichnet (...). Nach der Zustimmung des Lenkungsausschusses der Projektbeteiligten vom 10. Dezember 2009 (...) wurden die ersten Arbeiten ausgeschrieben.

Die Parteien streiten insbesondere darüber, ob die urheberpersönlichkeitsrechtlichen Interessen die Eigentümerinteressen der Beklagten überwiegen (wird ausgeführt).

Die Parteien haben in erster Instanz außerdem darüber gestritten, ob die Ansprüche des Klägers verjährt oder verwirkt sind und ob der Planfeststellungsbeschluss der Geltendmachung urheberrechtlicher Ansprüche entgegensteht (§ 75 Abs. 2 VwVfG iVm §§ 18, 18c AEG).

\section{Urteil des Landgerichts}

Das Landgericht Stuttgart hat die Klage auf Unterlassung des Abbruchs der Flügelbauten und der Treppenanlage in der großen Schalterhalle mit Urteil vom 20. Mai 2010 abgewiesen.

1. Der Kläger habe ein Rechtsschutzbedürfnis. Dem stehe auch das eisenbahnrechtliche Planfeststellungsverfahren nicht entgegen. Er sei als Miterbe berechtigt, die urheberrechtlichen Unterlassungsansprüche geltend zu machen. Das Bahnhofsge- bäude weise einen hohen schöpferischen Eigentümlichkeitsgrad auf, es sei in Deutschland und Europa als architektonische Meisterleistung anerkannt. Der Urheberschutz ende gemäß § 64 UrhG am 31. Dezember 2026.

2. Der Planfeststellungsbeschluss hindere nicht die Geltendmachung von urheberrechtlichen Unterlassungsansprüchen, da der Planfeststellungsbeschluss keine privatrechtlichen Rechte und Befugnisse übertrage, weshalb auch die Geltendmachung urheberrechtlicher Unterlassungsansprüche nicht ausgeschlossen sei. Die Ansprüche seien nicht verjährt oder verwirkt.

3. Der Kläger könne keine Unterlassung verlangen, da die Abwägung überwiegende Änderungsinteressen des Eigentümers ergebe. Es bestünden wegen der hohen Gestaltungshöhe zwar gesteigerte urheberrechtliche Interessen an einer Erhaltung, der Abriss sei auch ein schwerer Eingriff in das konzipierte Gesamtwerk, wenn auch wesentliche Teile des Bauwerks erhalten blieben, da der ästhetische Eindruck von der Stadtseite her nicht verändert werde. Das Erhaltungsinteresse sei jedoch im Hinblick auf den Zeitablauf von mehr als 54 Jahren seit dem Tod des Urhebers Paul Bonatz abgeschwächt, zudem belege der Architektenvertrag, dass bei der Planung der Vorrang des Gebäudezwecks hingenommen worden sei. Dem Erhaltungsinteresse stünden gewichtige Interessen des Eigentümers gegenüber. Die Beklagten könnten sich auf ihr Interesse an einer bestimmungsgemäßen und verkehrsgerechten Nutzung berufen, welches insbesondere im Hinblick auf das Alter des Bauwerks und die veränderten Anforderungen des Schienenverkehrs eine Weiterentwicklung des Zweckbaus erforderlich mache. Angesichts der Billigung des Projekts durch die demokratisch legitimierten Hoheitsträger der Stadt Stuttgart und des Landes Baden-Württemberg sowie im Hinblick auf den erlassenen Planfeststellungsbeschluss bestünden öffentliche Interessen an einer Umsetzung. Die geplante Umwandlung des Kopfbahnhofs in einen unterirdischen Durchgangsbahnhof führe zu einem Funktionsverlust der Flügelbauten, zumal Paul Bonatz seinen künstlerischen Schwerpunkt auf die der Stadt zugewandten Gebäudeteile gelegt habe. (...)

\section{Berufung des Klägers}

Mit der Berufung will der Kläger weiterhin eine Verurteilung im erstinstanzlich beantragten Umfang erreichen, bezüglich des Nordflügels wird nunmehr der Wiederaufbau verlangt. Er rügt eine fehlerhafte Rechtsanwendung. Das landgerichtliche Urteil weise Rechtsfehler auf, denn

- die zergliedernde Beurteilung des Bauwerkes in wesentliche Teile (Schalterhallen, Säulenhallen, Kopfbahnsteighalle, Bahnhofsturm) und Bauteile mit untergeordneter Bedeutung (Flügel, Treppe),

- die Schwächung des Urheberrechts durch die bisherige Ablaufzeit, 
- die Einbeziehung der Modernisierungsinteressen,

- und die Beschränkung darauf, ob der Vorhabenträger seine Ermessensentscheidung ordnungsgemäß ausgeübt habe, weil damit eine Beschränkung auf eine bloße Willkürprüfung verbunden sei,

entsprächen nicht der Rechtslage (wird ausgeführt).

\section{Anträge im Berufungsverfahren}

Der Kläger beantragt nunmehr:

Das Urteil des Landgerichts Stuttgart wird abgeändert: Die Beklagten werden verurteilt,

- den Nord-West-Flügel (Richtung Heilbronner Straße) des Stuttgarter Hauptbahnhofs wieder aufzubauen, und zwar in dem Zustand, wie er sich vor dem Abriss befunden hat;

- es zu unterlassen, im Zuge der Realisierung des Bahnprojekts Stuttgart 21 in Stuttgart

a. den Süd-Ost-Flügel (Schlossgartenflügel) und/oder

b. die Treppenanlage in der Großen Schalterhalle (und damit verbunden eine große Fläche im Boden der Kopfbahnsteighalle) des Hauptbahnhofs in Stuttgart ganz oder teilweise abzureißen oder abreißen zu lassen.

Die Beklagten beantragen:

Die Berufung wird zurückgewiesen.

\section{Berufungserwiderung der Beklagten}

Die Beklagten verteidigen das landgerichtliche Urteil. Das Landgericht habe eine zutreffende Interessenabwägung vorgenommen und dabei richtig zugunsten der Beklagten entschieden. (wird ausgeführt).

\section{B. Zulässigkeit und Begründetheit der Berufung}

Die Berufung ist zulässig, bleibt aber in der Sache ohne Erfolg. Der geltend gemachte Unterlassungsanspruch (§ 97 Abs. 1 iVm $\S \S 14$ Abs. 1, 39 Abs. 1, 28 Abs. 1 UrhG und dem urheberrechtlichen Änderungsverbot) besteht nicht, da die Interessen der Beklagten an einem Teilabriss die Bestands- und Integritätsinteressen des Klägers überwiegen. Der Kläger kann deshalb auch nicht den Wiederaufbau des Nordflügels verlangen.

\section{Aktivlegitimation des Klägers}

Die Aktivlegitimation des Klägers - also die dem Grunde nach gegebene Rechtsinhaberschaft bezüglich der geltend gemachten urheberrechtlichen Unterlassungsansprüche - ist zwischen den Parteien unstreitig. Der Kläger ist ausweislich der vorgelegten Kopien der Erbscheine über seine Mutter D. Miterbe des am 20. Dezember 1956 verstorbenen Architekten Paul Bonatz (...). Er ist gemäß § 2039 BGB iVm §§ 28 Abs. 1, 64 UrhG berechtigt, die auf ihn übergegangenen urheberpersönlichkeitsrechtlichen Interessen seines Großvaters geltend zu machen. Eigene Interessen des Klägers, die nicht durch die Rechtsnachfolge (also die Erbschaft, §§ 1922 ff. BGB) vermittelt sind, können insoweit allerdings nicht berücksichtigt werden (BGH GRUR 1989, 106 [107] - Oberammergauer Passionsspiele II ). Die übrigen Miterben haben gegenüber den Beklagten erklärt, dass sie das Ergebnis dieses Rechtsstreits gegen sich gelten lassen.

\section{Passivlegitimation der Beklagten}

Die Passivlegitimation der Beklagten steht ebenfalls nicht im Streit.

1. Die Beklagte Ziff. 1 ist zwar nicht Eigentümerin des Bahnhofs und auch nicht Trägerin des Bauvorhabens. Sie trägt aber selbst vor, dass sie in die Planungen involviert ist (...). Die Auslobung des Architektenwettbewerbs erfolgte durch die Beklagte Ziff. 1 (...). Sie ist jedenfalls als Konzernmutter in der Lage, Einfluss auf das Projekt zu nehmen (§§ $15 \mathrm{ff}$. AktG), sie agiert entsprechend in der Öffentlichkeit (...). Ausweislich der Anlage K 9 wurden die Entscheidungen zur Durchführung des Projekts in den Leitungsgremien der Projektbeteiligten am 10. Dezember 2009 getroffen (...). Hierdurch werden gegebenenfalls bestehende urheberrechtliche Ansprüche des Klägers tangiert. Die Beklagte Ziff. 1 hat außerdem im Termin vor dem Senat ausdrücklich klargestellt, dass sie ihre Passivlegitimation nicht in Frage stellt.

Wenn im Folgenden vom Eigentümer die Rede ist, gilt dies daher jeweils auch für die Beklagte Ziff. 1.

2. Die Beklagte Ziff. 2 ist als Eigentümerin des Bahnhofs und Vorhabenträgerin passiv legitimiert, denn durch die von ihr getroffenen Maßnahmen werden gegebenenfalls bestehende urheberrechtliche Ansprüche des Klägers beeinträchtigt.

\section{Ausschlusswirkung des Planfeststel- lungsbeschlusses}

Der Senat lässt offen, ob schon der Planfeststellungsbeschluss vom 28. Januar 2005 die Geltendmachung urheberrechtlicher Unterlassungsansprüche verhindert.

1. Nach § 75 Abs. 2 Satz 1 VwVfG sind Ansprüche auf Unterlassung des Vorhabens ausgeschlossen, wenn der Planfeststellungsbeschluss unanfechtbar geworden ist. Die Planfeststellung hat insoweit Gestaltungswirkung, als dass alle öffentlich-rechtlichen Rechtsbeziehungen zwischen dem Träger des Vorhabens und den durch den Plan in ihren Rechten betroffenen Dritten positiv beziehungsweise negativ gestaltet werden (BVerwG NVwZ 2008, 561 Rn. 14; Kopp/Ramsauer VwVfG, 10. Aufl. 2008, 
$\S 75$ Rn. 8 und 9). Folge der Planfeststellung ist weiter eine Duldungswirkung, indem öffentliche und private Unterlassungsund Beseitigungsansprüche ausgeschlossen werden (BVerwGE 58, 281 [285]; BVerwGE 50, 220 [226 - 227]; BVerwG DÖV 1981, 719 [720]). In der Kommentarliteratur wird dazu ausgeführt, Folge der Planfeststellung sei auch der Ausschluss von sonst nach bürgerlichem Recht in Betracht kommenden Unterlassungs-, Änderungs- und Beseitigungsansprüchen, insbesondere gemäß §§ 823, 861 ff., 903, 906, 907, 1004 BGB (Kopp/Ramsauer VwVfG, 10. Aufl. 2008, § 75 Rn. 10; Bonk/Neumann in: Stelkens/Bonk/Sachs, VwVfG, 7. Aufl. 2008, § 75 Rn. 62; Dürr in: Knack/Hennecke, VwVfG, 9. Aufl. 2010, § 75 Rn. 38 und Fn. 97, ebenso OVG Lüneburg NVwZ-RR 1997, 90 [91]). Sinn und Rechtfertigung der Duldungswirkung ist der Schutz der durch die Abwägungsentscheidung getroffenen Interessenabwägung und der dadurch erfolgende Interessenausgleich, in den nicht mehr aufgrund eines privaten Einzelinteresses eingegriffen werden soll (Kämper in: Bader/Ronellenfitsch, VwVfG, 2010, § 75 Rn. 13). Daraus kann man den Schluss ziehen, dass urheberrechtliche Unterlassungsansprüche wegen der strukturellen Ähnlichkeit mit Ansprüchen aus Eigentum von der Duldungswirkung ebenfalls erfasst werden (vergleiche z.B. BVerwG NVwZ 2008, 561).

Für den Ausschluss urheberrechtlicher Unterlassungsansprüche spricht der Wortlaut von $\S 75$ Abs. 2 Satz 1 VwVfG (...), denn der Antrag des Klägers auf Unterlassung des Abbruchs zielt auf Unterlassung des Vorhabens. Dafür spricht auch der mit einem Planfeststellungsverfahren verfolgte Zweck einer Konzentration aller maßgeblichen Belange in einem behördlichen Verfahren. Der Planfeststellungsbeschluss kann insoweit auch den Unterlassungsanspruch des Klägers als nachteilig Planbetroffener erfassen, jedoch nicht eventuelle Schadenersatz- und Ausgleichsansprüche.

2. Die Rechtsprechung des $B G H$ und des BVerwG geht aber auch übereinstimmend davon aus, dass nur solche Auswirkungen erfasst werden, auf die sich die Planfeststellung bezieht und dass keine (weitergehenden) privatrechtlichen Befugnisse eingeräumt werden. Der Planfeststellungsbeschluss wirkt nur in den durch das Planfeststellungsrecht gezogenen Grenzen auf die Gestaltung der privaten Rechtsbeziehungen des Vorhabenträgers ein. Durch die Planfeststellung erlangt der Vorhabenträger private Rechte oder Befugnisse, die er nicht ohnehin schon innehat, auch dann nicht, wenn er solcher Rechte oder Befugnisse bedarf, um das geplante Vorhaben zu verwirklichen - dies gilt umgekehrt auch für Ansprüche des Rechtsinhabers (BVerwG NVwZ 1994, 682 für die Klage eines Architekten gegen einen Planfeststellungsbeschluss, der in der geänderten Gestaltung des Elbtunnels seine Urheberpersönlichkeitsrechte verletzt sah). Der Planfeststellungsbeschluss überträgt keine privatrechtlichen Rechte und Befugnisse und führt selbst keine unmittelbaren privatrechtlichen Veränderungen herbei $(B G H$ NVwZ 2004, 377 [378]). Fraglich ist aber die Reichweite dieser Rechtsprechung. Insoweit besteht Einigkeit, dass der Enteignungsentschädigungsanspruch erst aufgrund des Zugriffs auf die benötigten Grundstücke entsteht, die Planfeststellung aber eine sogenannte enteignungsrechtliche Vorwirkung hat (vergl. BGH NJW 2005, 660; BGH NJW 1999, 1247 [1248]; BGHZ 132, 63 [69]; BVerwG NJW 2008, 561 Rn. 14).

\section{Bahnhof als Werk der Baukunst ( $\S 2$ Abs. 1 Nr. 4 UrhG) - Schöpfungs-, Ge- staltungshöhe}

Beim Stuttgarter Bahnhof - insbesondere auch den Seitenflügeln und der Treppenanlage in der großen Schalterhalle - handelt es sich um ein schutzfähiges Werk der bildenden Kunst im Sinne des § 2 Abs. 1 Nr. 4, Abs. 2 UrhG.

\section{Rechtliche Vorgaben aus $\S 2$ Abs. 1 Nr. 4, Abs. 2 UrhG}

Ein Bauwerk oder ein Teil eines Bauwerks genießt nach § 2 Abs. 1 Nr. 4 UrhG urheberrechtlichen Schutz, wenn es aus der Masse des alltäglichen Bauschaffens herausragt, also eine ausreichende schöpferische Individualität, eine künstlerische Qualität aufweist (BGH GRUR 2008, 984 [985 Rn. 15 f.] - St. Gottfried; $B G H$ GRUR 1999, 230 [231] - Treppenhausgestaltung; BGH GRUR 1982, 107 [109] - Kirchen - Innenraumgestaltung; Schulze NZBau 2007, 537; Goldmann GRUR 2005, 639 [640]).

Für die Beurteilung der Schöpfungshöhe eines Werkes der Baukunst ist der ästhetische Eindruck maßgeblich, den das Werk nach dem Durchschnittsurteil des für Kunst empfänglichen und mit Kunstfragen einigermaßen vertrauten Menschen vermittelt. Es kommt nicht auf die ästhetischen Feinheiten an, die ein auf dem Fachgebiet arbeitender Fachmann herausfühlt. Deshalb ist für die Feststellung der Schöpfungshöhe die Einholung eines Sachverständigengutachtens regelmäßig nicht erforderlich (BGH GRUR 2008, 984 [986 Rn. 20] - St. Gottfried ; BGH GRUR 1982, 107 [110] - Kirchen-Innenraumgestaltung; BGH GRUR 1974, 675 [677] - Schulerweiterung; $B G H Z$ 24, 55 [68] - Ledigenheim ).

Die Schutzfähigkeit eines Werkes kann nicht vereinbart werden, diese ist vielmehr der Dispositionsbefugnis der Parteien entzogen (BGH GRUR 1991, 533 - Brown Girl II; OLG Hamm WRP 1983, 352 [353] - Chiceria Modeladen; OLG Karlsruhe GRUR 1984, 521 [522] - Atari Spielkassetten). Entweder erreicht der zu beurteilende Gegenstand die im Urheberrecht verlangten Schutzvoraussetzungen oder er erreicht sie nicht. Die Schutzfähigkeit ist von Amts wegen zu überprüfen (BGH GRUR 1991, 533 - Brown Girl II ; BGH GRUR 1988, 812 [814] - Ein bisschen Frieden; OLG Hamm WRP 1983, 352 [353] - Chiceria Modeladen; OLG Karlsruhe GRUR 1984, 521 [522] - Atari Spielkassetten).

\section{Anwendung dieser Vorgaben auf den vorlie- genden Sachverhalt}

Beim Stuttgarter Hauptbahnhof handelt es sich um ein architektonisch herausragendes Werk, das eine hohe schöpferische Qualität aufweist. 
a. Die besondere Eigentümlichkeit ergibt sich aus der Verwendung verschiedener kubischer Formen, die in einer symmetrischen und asymmetrischen Verschachtelung zu einem komplexen Gebäude angeordnet worden sind. Der Kläger hat zutreffend ausgeführt, dass der hohe schöpferische Eigentümlichkeitsgrad durch die Zusammenfassung großer und unterschiedlich gestalteter Gebäudekuben mit unterschiedlichen Längen, Breiten und Höhen entsteht. Diese kulminieren in einem seitlich eingebundenen, hoch aufragenden quadratischen Uhrenturm, der die Königstraße als eine der wichtigsten Straßen Stuttgarts beherrscht. Die besondere Schöpfungshöhe zeigt sich auch in der Fassadengestaltung, die wiederum die kubischen Formen widerspiegelt, aber durch ihre Strukturierung und die Pfeiler, Bögen sowie Fenster Details von hoher schöpferischer Eigentümlichkeit enthält. Die Besonderheit wird insbesondere durch die Kombination der monumentalen Bauweise mit klassischem Bauschmuck und fortschrittlichen Elementen geprägt.

$$
\text { b. (...) }
$$

c. Die Charakterisierung im Gutachten vom 22. Oktober 1986 zur Eintragung in das Denkmalbuch beschreibt den Bahnhof treffend als eine der wichtigsten Schöpfungen der damaligen Architektur, die zuerst mit voller Klarheit den Wert des Kubus für die neue Architektur erkannt hat, die ungezwungen und malerisch anmutet, gleichzeitig aber die Teile streng in kubische Formen gebannt und aneinandergebunden hat. Das Gebäude verkörpere den Zweckgedanken dieses wichtigen Verkehrsbaus - Sammlung der Menschenmassen und Zuleitung zu einem Ziel, Brennpunkt für die Strahlen des Verkehrs. Die für den Durchgangsverkehr nicht günstige Form des Kopfbahnhofs wurde durch die Gebäude und die gewählten Formen zu einem Anregungsmittel stärkster Wirkung (...). Auch ein Beitrag von Paul Bonatz selbst hat die schöpferischen Eigentümlichkeiten des Bahnhofs prägnant beschrieben, indem er auf die einfachen kubischen Formen ohne sichtbare Dächer, auf die besonderen Gestaltungselemente der Pfeiler und Fenster und die besondere Flächengliederung verwiesen hat (...).

Es kann dahingestellt bleiben, ob die Treppenanlage überhaupt urheberrechtlichen Schutz besitzt, denn jedenfalls überwiegen auch insoweit die Abänderungsinteressen der Beklagten (wie nachfolgend im Einzelnen unter VIII. ausgeführt). Zwischen den Parteien ist unstreitig, dass die eigentlichen gestalterischen Elemente durch den Austausch der Treppe im Jahre 1974 (die geschwungenen seitlichen Wangen und Handläufe sind entfallen, ebenso die Säulen rechts und links der Treppe) nicht mehr vorhanden sind (...). Der Kläger leitet die Schöpfungshöhe insoweit aus dem harmonischen Erscheinungsbild der Eingangshalle mit einer vorhandenen Treppe her. Schon die Raumwirkung der Eingangshalle (mit oder ohne Treppe) kann eine besondere Gestaltungshöhe begründen, die verändert würde, selbst wenn man daran zweifeln mag, ob hierdurch das Gesamtkunstwerk beeinträchtigt ist. d. Die Beklagten haben die herausragende Schöpfungshöhe nicht bestritten, sondern ausgeführt, sie würden die hohe Qualität der geschaffenen Architektur anerkennen (...). Das Landgericht sei in seiner Entscheidung in zutreffender Weise davon ausgegangen, dass es sich bei dem Bonatz-Bau um ein urheberrechtlich geschütztes Bauwerk von hohem Rang handelt (...).

\section{Urheberrechtliches Änderungsverbot (rechtliche Vorgaben)}

\section{Abgrenzung zwischen Entstellungsverbot ( $\S 14$ UrhG) und Änderungsverbot (§ 39 UrhG)}

Der Streit über die Abgrenzung zwischen dem Entstellungsverbot nach § 14 UrhG und dem Änderungsverbot gemäß § 39 UrhG kann offenbleiben. Die Rechtsprechung des $B G H$, welcher der Senat folgt, sieht ein allgemeines urheberrechtliches Änderungsverbot (gegenüber den Nichtwerknutzungsberechtigten) in Anknüpfung an eine Formulierung des Reichsgerichts ( $R G Z$ 69, 242 [244]) vom Gesetz stillschweigend als selbstverständlich vorausgesetzt und dessen Grundlage im Wesen und Inhalt des Urheberrechts (BGH GRUR 2008, 984 [986 Rn. 23] - St. Gottfried; vergl. auch die praktisch identischen Formulierungen in BGH GRUR 1982, 107 [109] - Kirchen-Innenraumgestaltung; BGH GRUR 1974, 675 [676] - Schulerweiterung; BGH GRUR 1971, 35 [37] - Maske in Blau). Danach gibt es neben den normierten Ansprüchen in §§ 14, 39 UrhG ein allgemeines urheberrechtliches Änderungsverbot (ablehnend demgegenüber Wandkte/Grunert in: Wandtke/Bullinger, Praxiskommentar zum Urheberrecht, 3. Aufl. 2009, § 39 Rn. 3: Überlegungen zu einem allgemeinen urheberrechtlichen Änderungsverbot seien seit der Einfügung von § 14 UrhG obsolet).

Frühere Entscheidungen haben ausgeführt, beide Ansprüche stünden selbständig nebeneinander (BGH GRUR 1982, 107 [109] - Kirchen-Innenraumgestaltung; BGH GRUR 1999, 230 [231] - Treppenhausgestaltung, differenziert zwar zwischen § 14 UrhG und § 39 UrhG, stellt aber auch auf das allgemeine urheberrechtliche Änderungsverbot ab; grundlegend zum Verhältnis von $\S \S 14,39$ UrhG und zum allgemeinen Änderungsverbot Erdmann FS Piper 1996, 665 [668 f.]). In der Literatur wird auch vertreten, dass die beiden Normen nicht selbständig zu prüfen seien, sondern insgesamt auf den Regelungszusammenhang abzustellen sei (Schulze in: Dreier/Schulze, UrhG, 3. Aufl. 2008, § 39 Rn. 3). Eine scharfe Abgrenzung sei entbehrlich, da bei jeder Beeinträchtigung eines Werkes letztlich eine Interessenabwägung entscheide (Steinbeck GRUR 2008, 988; Goldmann GRUR 2005,639 [642]).

Die Abgrenzung kann offen bleiben, weil anerkannt ist, dass sowohl im Rahmen des Schutzes vor Entstellungen und anderen Beeinträchtigungen ( $\$ 14$ UrhG), als auch im Rahmen von Werkänderungen ( 39 UrhG) eine Interessenabwägung vorzu- 
nehmen ist, ob ein urheberrechtlicher Integritätsschutz zuzubilligen ist, und im vorliegenden Fall die übrigen Voraussetzungen beider Vorschriften jeweils unstreitig zu bejahen sind.

Der Anspruch aus $\S 39$ UrhG verlangt einen Eingriff in die Substanz und richtet sich gegen den jeweiligen Werknutzungsberechtigten. Ansprüche nach § 14 UrhG erfordern einen Eingriff in den ästhetischen Gesamteindruck und können gegenüber jedermann geltend gemacht werden.

Weil die Ansprüche auch aus § 14 UrhG und dem allgemeinen urheberrechtlichen Änderungsverbot hergeleitet werden, bedarf es keiner Entscheidung zur generellen Anwendbarkeit von § 39 UrhG auf den Architektenvertrag vom 30 . Mai 1913 (...). Im Übrigen hat der Kläger zutreffend darauf hingewiesen, dass der von den Beklagten zitierte § 132 UrhG nicht einschlägig ist, da die Bestimmung nur für urheberrechtliche Nutzungsverträge gilt (vergleiche nur Braun/Jani in: Wandtke/Bullinger, Praxiskommentar zum Urheberrecht, 3. Aufl. 2009, § 132 Rn. 2), hier aber gesetzliche Ansprüche wegen Eingriffen in das geschaffene Werk geltend gemacht werden. Die ausgefeilte Rechtsprechung zu entstellenden Architektureingriffen wäre Makulatur, wenn die Ansicht der Beklagten richtig wäre.

\section{Inhalt und Prüfung des urheberrechtlichen Ände- rungsverbots}

Das urheberrechtliche Änderungsverbot besagt, dass der Eigentümer des Werkoriginals grundsätzlich keine in das fremde Urheberrecht eingreifenden Änderungen an dem ihm gehörenden Original vornehmen darf. Der Urheber hat grundsätzlich ein Recht darauf, dass das von inm geschaffene Werk, in dem seine individuelle künstlerische Schöpferkraft ihren Ausdruck gefunden hat, der Mit- und Nachwelt in seiner unveränderten Gestalt zugänglich gemacht wird (BGH GRUR 2008, 984 [986 Rn. 23] - St. Gottfried; $B G H$ GRUR 1999, 230 [231] - Treppenhausgestaltung; BGH GRUR 1974, 675 [676] - Schulerweiterung; BGH GRUR 1971, 35 [37] - Maske in Blau).

a. In einem ersten Prüfungsschritt muss eine Beeinträchtigung des Werks festgestellt werden. Das Änderungsverbot richtet sich gegen eine Verletzung des Bestands und der Unversehrtheit des Werks in seiner konkret geschaffenen Gestaltung, der Begriff der Werkänderung erfordert daher grundsätzlich einen Eingriff in die Substanz der urheberrechtlichen Gestaltung (BGH GRUR 2008, 984 [986 Rn. 23] - St. Gottfried; BGH GRUR 1982, 107 [109] - Kirchen-Innenraumgestaltung). Insoweit reicht es aus, wenn der Betrachter annehmen kann, das (veränderte) Werk stamme vom ursprünglichen Urheber (BGH GRUR 2008, 984 [986 Rn. 24] - St. Gottfried), wenn der Eingriff den Raumeindruck verfälscht (BGH GRUR 1999, 230 [231] - Treppenhausgestaltung), wenn die ästhetische Wirkung des Gebäudes, sein Charakter erheblich verändert wird, eine bedeutsame Umgestaltung erfährt (BGH GRUR 1974, 675 [676 und 677] - Schulerweiterung).
Eine weitere Abgrenzung ist jedenfalls im konkreten Fall nicht erforderlich, denn es kommt unstreitig zu einem körperlichen und urheberrechtlich relevanten Substanzeingriff.

b. Auf der zweiten Stufe ist zu prüfen, ob die berechtigten Interessen des Urhebers gefährdet werden. Da eine bloße Gefährdung genügt, ist bereits das Vorliegen der Beeinträchtigung, also jede objektiv nachweisbare direkte oder indirekte Änderung des Werks, ein ausreichendes Indiz für die Eignung einer Gefährdung der berechtigten Urheberinteressen (Schulze in Dreier/Schulze, UrhG, 3. Aufl. 2008, § 14 Rn. 15; Dustmann in: Fromm/Nordemann, Urheberrecht, 10. Aufl. 2008, § 14 Rn. 15).

c. Der sich aus dem Zusammentreffen der Belange des Urhebers einerseits und der des Eigentümers andererseits ergebende Konflikt ist durch eine Abwägung der jeweils betroffenen Interessen im konkreten Einzelfall zu lösen, wobei das Bestands- und Integritätsinteresse des Urhebers an der Erhaltung des Werks und die Interessen des Eigentümers an einer Beeinträchtigung und Veränderung des Werks abzuwägen sind (plakativ: Erhaltungsinteresse versus Änderungsinteresse, $B G H$ GRUR 2008, 984 [986 Rn. 25] - St. Gottfried; BGH GRUR 1974, 675 [676] - Schulerweiterung; BGH GRUR 1971, 35 [37] - Maske in Blau). Das Urheberrecht und das Eigentumsrecht stehen sich insoweit zunächst gleichrangig gegenüber, der Vorrang ist im Wege der Interessenabwägung zu finden (Steinbeck GRUR 2008, 988; Wedemeyer FS Piper, 1996, 787 [793]).

aa. Für die Abwägung dieser Interessen hat die Rechtsprechung Kriterien entwickelt. Insoweit lassen sich aber keine starren und allgemeingültigen Regeln aufstellen, welche Änderungen zu gestatten sind; die Interessenabwägung kann zu einem engeren oder weiteren Freiheitsspielraum des Nutzers führen (BGH GRUR 1974, 675 [676] - Schulerweiterung; BGH GRUR 1971, 35 [37] - Maske in Blau; Schulze NZBau 2007, 611 [613]). Je nach Art der Werknutzung kann die Interessenabwägung unterschiedlich ausfallen (BGH GRUR 1989, 106 [108] - Oberammergauer Passionsspiele II).

(1) Der Urheber muss vertraglich eingeräumte Änderungsrechte oder Verwertungszwecke hinnehmen und kann sich insoweit nicht auf sein Erhaltungsinteresse berufen, es sei denn, es wird der unverzichtbare Kern seines Urheberpersönlichkeitsrechts tangiert, beispielsweise durch eine gröbliche Entstellung (BGH GRUR 1971, 269 [271] - Das zweite Mal; Schulze NZBau 2007, 611 [612]; Schulze in: Dreier/Schulze, UrhG, 3. Aufl. 2008, $\S 14$ Rn. 15; a.A. Wedemeyer FS Piper, 1996, 787 [791], der auch Entstellungen zulassen will).

(2) Ein maßgeblicher und wesentlicher Abwägungsfaktor ist der individuelle Schöpfungsgrad, der Rang des Werkes, denn das Interesse des Urhebers an der unveränderten Erhaltung seines Werkes wird von der Schöpfungshöhe beeinflusst - je größer die Gestaltungs-, Schöpfungshöhe ist, desto stärker sind die persönlichen Bindungen des Urhebers an sein Werk, ist das 
Erhaltungsinteresse höher zu bewerten (BGH GRUR 2008, 984 [986 Rn. 27] - St. Gottfried; BGH GRUR 1974, 675 [676] - Schulerweiterung; Erdmann FS Piper, 1996, 655 [672]). Je individueller und einmaliger, einzigartiger das Werk ist, desto weniger sind Änderungen zuzulassen.

Die Annahme eines hohen individuellen Schöpfungsgrades darf aber nicht dazu führen, dass Änderungen dann generell ausgeschlossen sind, weil ansonsten die von der höchstrichterlichen Rechtsprechung geforderte Interessenabwägung obsolet wäre und dies quasi zu einer enteignungsähnlichen Situation beim Werkeigentümer und Nutzungsberechtigten führen würde. Es gibt keinen absoluten und ausnahmslosen Vorrang des Erhaltungsinteresses bei überragender Schöpfungshöhe oder einzigartigen Werken. Der Vorwurf des Klägers, das landgerichtliche Urteil enthalte insoweit Widersprüche, greift deshalb nicht. Wesen einer Interessenabwägung ist gerade die Gewichtung und Bewertung der maßgeblichen und zu berücksichtigenden Abwägungspunkte.

Das künstlerische Ansehen des Urhebers soll dabei aber nach einer Auffassung in der Literatur keine Rolle spielen (Bullinger in: Wandtke/Bullinger, Praxiskommentar zum Urheberrecht, 3. Aufl. 2009, § 14 Rn. 17). Die Rechtsprechung berücksichtigt demgegenüber zu Recht den Rang der Werke auch mit Blick auf das künstlerische Ansehen des Urhebers (BGH GRUR 1989, 106 [107] - Oberammergauer Passionsspiele II; BGH GRUR 1982, 107 $[109,110]$ - Kircheninnenraumgestaltung; OLG München GRUR 1986, 460 [461] - Unendliche Geschichte).

(3) Das Erhaltungsinteresse hängt auch von der Art und dem Ausmaß des Eingriffs ab, beispielsweise auf eine Veränderung der Gesamtwirkung (BGH GRUR 2008, 984 [986 Rn. 28] - St. Gottfried; $B G H$ GRUR 1999, 230 [231 f.] - Treppenhausgestaltung; $B G H$ GRUR 1974, 675 [676] - Schulerweiterung; Schulze NZBau 2007, 611 [613]). Deshalb ist zu fragen, ob das Werk in seinen wesentlichen Zügen verändert wird (BGH GRUR 1971, 35 [37] - Maske in Blau). Auch eine Entstellung im Sinne von § 14 UrhG muss sich auf den künstlerischen Gesamteindruck und damit auf die diesen prägenden schutzfähigen Gestaltungselemente beziehen (BGH GRUR 1982, 107 [110] - Kirchen-Innenraumgestaltung). Wenn Gesamtcharakter, Grundkonzeption und künstlerische Substanz des Werks erhalten bleiben, ist der Eingriff zu dulden (BGH GRUR 1974, 675 [677] - Schulerweiterung).

(4) Die Urheberinteressen können Jahre und Jahrzehnte nach dem Tod des Urhebers an Gewicht verlieren, sie schwächen sich im Laufe der Jahre immer mehr ab und haben nicht notwendig dasselbe Gewicht wie zu Lebzeiten des Urhebers (BGH GRUR 2008, 984 [986 Rn. 29] - St. Gottfried; BGH GRUR 1989, 106 [107] - Oberammergauer Passionsspiele Il; in der Literatur wird auch von Verblassung, Abschwächung gesprochen). Insoweit sind tatsächliche Feststellungen erforderlich, dass sich das Urheberinteresse verringert hat (BGH GRUR 2008, 984 [986 Rn. 29] - St. Gottfried).
(5) Weitere (über die Rechte aus Art. 14 GG hinausgehende) grundrechtlich geschützte Interessen des Eigentümers sind ebenfalls zu beachtende Abwägungskriterien (BGH GRUR 2008, 984 [987 Rn. 30 - 35] - St. Gottfried).

(6) Der Gebrauchszweck und die bestimmungsgemäße Verwendung des Bauwerks spielen bei Werken der Baukunst eine wesentliche Rolle, denn der Urheber muss mit wechselnden Bedürfnissen des Eigentümers und des Lebens rechnen. Der Urheber eines Bauwerks weiß, dass der Eigentümer das Bauwerk für einen bestimmten Zweck verwenden möchte; er muss daher damit rechnen, dass sich aus wechselnden Bedürfnissen des Eigentümers ein Bedarf nach Veränderungen ergeben kann (BGH GRUR 2008, 984 [987 Rn. 38] - St. Gottfried; BGH GRUR 1999, 420 [426] - Verbindungsgang; BGH GRUR 1974, 675 [676] - Schulerweiterung). Das soll aber nicht bedeuten, dass stets solche Änderungen erlaubt sind, die der bestimmungsgemäße Gebrauchszweck erfordert, weil sich dann eine Interessenabwägung erübrigen würde - erforderlich ist auch insoweit eine auf den konkreten Einzelfall bezogene Interessenabwägung ( $B G H$ GRUR 1974, 675 [677 f.] - Schulerweiterung). Insgesamt wird bei Bauwerken den Nutzungsinteressen des Eigentümers aber eine größere Bedeutung zugemessen als bei anderen Werkarten (Schulze NZBau 2007, 611 [613]; Erdmann FS Piper, 1996, 655 [670] spricht von einer besonderen Änderungsanfälligkeit und [S. 672] von einem tendenziellen Zurücktreten der Urheberinteressen). In der Literatur wird ausgeführt, wenn der Gebrauchszweck aufrechtzuerhalten sei, seien Änderungen eher zuzulassen, würden Änderungen aus nutzungserhaltenden, wirtschaftlichen oder technischen Gründen keine erheblichen Entstellungen bewirken, setze sich in der Regel das Eigentümerinteresse durch (Wandtke/Grunert in: Wandtke/Bullinger, Praxiskommentar zum Urheberrecht, 3. Aufl. 2009, § 39 Rn. 22; Honschek GRUR 2007, 944 [947]; OLG München ZUM 1996, 165 [166] - Dachgauben [juris Rn. 12]). Bauwerke dürften grundsätzlich abgerissen werden, zumal es dem Eigentümer vorbehalten bleiben müsse, mit seinem Grundstück nach Belieben zu verfahren (Schulze in: Dreier/Schulze, UrhG, 3. Aufl. 2008, § 14 Rn. 28).

(7) Zu berücksichtigen sind auch Modernisierungsinteressen. Der BGH führt dazu bezüglich einer Operette aus, im Hinblick auf Realitäten (des aufführenden Theaters - räumliche Verhältnisse, Zusammensetzung des künstlerischen Personals) und einen Wandel des Publikumsgeschmacks bestünde ein Modernisierungsspielraum (BGH GRUR 1971, 35 [38] - Maske in Blau). Ulmer bemerkt dazu, es müsse dem Regisseur gestattet sein, das Stück mit neuen Augen, mit den Augen von heute zu sehen (Ulmer GRUR 1971, 40 [41]).

(8) Auch wirtschaftliche Gesichtspunkte können von Bedeutung sein, etwa die Veränderung eines Flachdachs in ein geneigtes Dach nach aufgetretenen Wasserschäden (OLG München ZUM 1996, 165 [166] - Dachgauben [juris Rn. 12]; Wedemeyer FS Piper, 1996, 787 [788]; Bullinger in Wandtke/Bullinger, Praxiskommentar zum Urheberrecht, 3. Aufl. 2009, § 14 Rn. 35). 
(9) In die Abwägung dürfen grundsätzlich auch Allgemeininteressen einfließen, allerdings ist insoweit eine differenzierte Betrachtung geboten (vergl. dazu nachfolgend unter VI. 1.)

(10) Bloße ästhetische und geschmackliche Gründe berechtigen nicht zu einer Veränderung, sie sind gegenüber dem Erhaltungsinteresse des Urhebers unbeachtlich (BGH GRUR 2008, 984 [987 Rn. 36] - St. Gottfried; BGH GRUR 1999, 230 [232] - Treppenhausgestaltung).

bb. Die Abwägung bedarf (ebenso wie die Feststellung der Schöpfungshöhe) nicht der Einholung eines Sachverständigengutachtens. Hier kommt es nicht auf die ästhetischen Feinheiten an, die ein auf dem Fachgebiet arbeitender Fachmann herausfühlt, sondern auf den ästhetischen Eindruck, den das Werk nach dem Durchschnittsurteil des für Kunst empfänglichen und mit Kunstdingen einigermaßen vertrauten Menschen vermittelt (BGH GRUR 2008, 984 [986 Rn. 20] - St. Gottfried; BGH GRUR 1982, 107 [110] - Kirchen-Innenraumgestaltung; BGH GRUR 1974, 675 [677] - Schulerweiterung; $B G H Z$ 24, 55 [68] - Ledigenheim).

\section{Die einzelnen Berufungsangriffe zu den zu berücksichtigenden Kriterien}

\section{Berücksichtigungsfähigkeit von Interessen der Allgemeinheit, öffentlichen Interessen}

Soweit der Kläger die Auffassung vertritt, die von den Beklagten geltend gemachten öffentlichen (insbesondere städtebaulichen) Allgemeininteressen dürften als bloße Drittinteressen im Rahmen der Abwägung nicht berücksichtigt werden, kann dem der Senat so nicht folgen. Es ist vielmehr zu differenzieren: Die von den Beklagten geltend gemachten städtebaulichen Gründe (freiwerdende Flächen für ein neues Stadtviertel) sind allerdings aus rechtlichen und tatsächlichen Gründen nicht relevant. Zu berücksichtigen sind aber die Interessen an einer Modernisierung des Bahnhofs und der Verkehrsinfrastruktur, denn bei Letzteren handelt es sich um eigene Interessen und Pflichten der Beklagten.

a. Der BGH hat in seinem Urteil vom 31. Mai 1974 eine tatrichterliche Würdigung gebilligt, die öffentliche Interessen berücksichtigt hatte. Die Entscheidung führt dazu aus, dass den Interessen des Schulträgers und der Öffentlichkeit an einer im Rahmen des Gebrauchszwecks liegenden Schulbauerweiterung der Vorrang einzuräumen sei (BGH GRUR 1974, 675 [677] - Schulerweiterung). Allerdings sind die Interessen der Öffentlichkeit (also die Allgemeininteressen) nur in der Wiedergabe der Gründe des Berufungsurteils genannt (BGH GRUR 1974, 675 [677] - Schulerweiterung), in der eigenen Würdigung spricht das Urteil des $B G H$ nur von den Interessen des Schulträgers (BGH GRUR 1974, 675 [678] - Schulerweiterung). Es wurde also soweit ersichtlich bislang nicht ausdrücklich höchstrichterlich entschieden, dass und in welchem Umfang auch öffentliche Belange und Allgemeininteressen bei der Interessenabwägung von Urheber- und Eigentümerinteressen berücksichtigt werden können, zumal zu bedenken ist, dass ein Schulträger anders als eine privatrechtlich organisierte Aktiengesellschaft, wie dies bei den Beklagten der Fall ist (vergl. nur Art. 87e GG), per se verpflichtet ist, öffentliche Interessen wie eigene Interessen zu berücksichtigen.

b. Der Senat bejaht die grundsätzliche Möglichkeit der Einstellung von Allgemeininteressen in die vorzunehmende Einzelfallabwägung.

aa. Zwar sind das Bestands- und Integritätsinteresse des Urhebers an der Erhaltung des Werks und die Interessen des Eigentümers an einer Beeinträchtigung und Veränderung des Werks (BGH GRUR 2008, 984 [986 Rn. 25] - St. Gottfried) gegeneinander abzuwägen, was vordergründig dafür sprechen könnte, dass Drittinteressen insoweit irrelevant sind, nachdem diese dort nicht genannt werden.

bb. Diese Sichtweise lässt aber außer Acht, dass der Eigentümer bei Baumaßnahmen und urheberrechtlich relevanten Veränderungen verpflichtet sein kann, auch öffentliche Belange zu berücksichtigen.

Wenn der Eigentümer (rechtlich) verpflichtet ist, auf Drittinteressen - insbesondere öffentliche Interessen und Belange des Gemeinwohls - Rücksicht zu nehmen (schon im Rahmen des Planungsverfahrens oder durch Vorgaben und Festlegungen des Planfeststellungsbeschlusses), würde eine Nichtberücksichtigung öffentlicher Belange im Rahmen der Interessenabwägung dazu führen, dass der Eigentümer keine Möglichkeit hat, die gegenläufigen Interessenlagen auszugleichen. Denn eine Nichtberücksichtigung entsprechender Interessen könnte dazu führen, dass der Eigentümer einerseits gegenüber dem Urheber verpflichtet wäre, die Sache (hier den Bahnhof) unverändert zu erhalten, während ihn andererseits Vorgaben aus Gründen des Gemeinwohls und öffentliche Interessen zu einer Abänderung zwängen (im Sachverhalt BGH GRUR 1974, 675 - Schulerweiterung, beispielsweise die Notwendigkeit einer Erweiterung einer zu klein gewordenen Schule), ohne dass dieser Interessenkonflikt im Rahmen einer wertenden Abwägung aufgelöst werden könnte.

cc. Die vom Eigentümer zu beachtenden öffentlichen Interessen und Gemeinwohlbelange sind deshalb im Rahmen der Abwägung als seine eigenen Interessen einzustellen. Auch der Grundsatz der Einheit der Rechtsordnung führt dazu, dass die von den Beklagten zu beachtenden Vorgaben und Belange als deren eigene Interessen bei der Abwägung berücksichtigt werden müssen, soweit eine Pflicht zur Beachtung besteht.

c. Allerdings darf die Berücksichtigung von Allgemeininteressen nicht dazu führen, dass diese Allgemeinwohlbelange in der Abwägung stets als besonders schwerwiegend eingeordnet werden (so aber die Beklagten unter Hinweis auf BVerfGE 52, 1 [32]), weil sich ansonsten eine Interessenabwägung weit- 
gehend erübrigen würde (ebenso BGH GRUR 1974, 675 [677 f.] - Schulerweiterung, zum Abwägungskriterium des Gebrauchszwecks und der bestimmungsgemäßen Verwendung). Auch insoweit gilt der Grundsatz, dass ein berücksichtigungsfähiges Abwägungskriterium im Rahmen der Einzelfallentscheidung zu gewichten ist.

Im hier zu entscheidenden Fall ist außerdem zu berücksichtigen, dass die Beklagten im Laufe des Planfeststellungsverfahrens unstreitig die Frage eines urheberrechtlichen Schutzes des Bahnhofs mit keinem Wort thematisiert haben - der Planfeststellungsbeschluss enthält lediglich Ausführungen zu denkmalschutzrechtlichen Belangen, setzt sich aber nicht mit dem unstreitig bestehenden Urheberschutz auseinander. Wer einerseits Urheberrechte (als berücksichtigungsfähige Privatbelange) missachtet, kann sich andererseits nicht ohne weiteres auf überragende Gemeinwohlinteressen berufen.

d. Damit eine Berücksichtigung erfolgen kann, muss aber eine echte (Rechts-) Pflicht zur Berücksichtigung der geltend gemachten öffentlichen Belange bestehen, weil ansonsten die Interessenabwägung durch Schaffung quasi künstlicher Belange manipuliert werden könnte.

aa. Tatsächliche, faktische oder vertraglich übernommene Pflichten zur Berücksichtigung von Allgemeinwohlbelangen haben außer Betracht zu bleiben. Ansonsten könnte sich der Vorhabenträger durch die Übernahme von (urheberrechtlich beeinträchtigenden) Veränderungsverpflichtungen einen ungerechtfertigten Abwägungsvorteil verschaffen. Im vorliegenden Fall wäre beispielsweise die Verpflichtung des Verkaufs des freiwerdenden Gleisgeländes an die Stadt im Rahmen der abgeschlossenen Verträge insoweit ein unzulässiger Vertrag zu Lasten des Urhebers als unbeteiligter Dritter - die städtebaulichen Interessen der Landeshauptstadt Stuttgart können deshalb nicht in die Abwägung zu Lasten des Klägers eingestellt werden, zumal insoweit die abzureißenden Teile überhaupt nicht tangiert sind.

bb. Hier besteht keine eigene (rechtliche) Verpflichtung der Beklagten zur Beachtung von städtebaulichen Belangen. Städtebauliche Interessen verfolgt insoweit allenfalls die an der Finanzierung beteiligte Landeshauptstadt Stuttgart.

(1) Soweit die Beklagten auf Art. 87e GG verweisen, trifft die Verpflichtung zur Beachtung der öffentlichen Gemeinwohlbelange nach dem insoweit eindeutigen Wortlaut und der Systematik der Norm den Bund (also die Bundesrepublik Deutschland), denn Art. 87e Abs. 4 GG führt aus, der Bund gewährleistet, dass dem Wohl der Allgemeinheit Rechnung getragen wird. Nachdem die Eisenbahnbetriebsunternehmen als Privatunternehmen in privatrechtlicher Form geführt werden, unterliegt die Bahn (also die Beklagten) nicht mehr dem immanenten Gemeinwohlauftrag, der ansonsten staatlicher Verwaltung eigen ist (vergleiche nur Uerpmann in: von Münch/Kunig, GGK III, 5. Aufl. 2003, Art. 87e Rn. 10 mwN). Die Eisenbahnunternehmen gehören nicht mehr zu den Grundrechtsverpflichteten.

(2) Auch die Bestimmungen des Raumordnungsgesetzes (ROG) begründen keine eigenen Pflichten der Beklagten, denn danach sind der Bund und die Länder zur Raumordnung aufgerufen, nicht jedoch ein (wenn auch im Staatseigentum stehendes) privatrechtlich organisiertes Unternehmen. Gleiches gilt für das von den Beklagten zitierte Landesplanungsgesetz, hier sind die oberste Landesplanungsbehörde und die Raumordnungsbehörden zur Planung aufgerufen.

(3) Die Vorgaben des Allgemeinen Eisenbahn Gesetzes (AEG) zur Planfeststellung begründen ebenfalls keine originären Pflichten der Beklagten, denn der Planfeststellungsbeschluss wird durch das Eisenbahnbundesamt erlassen, dieses ist originär und in eigener Zuständigkeit zur Abwägung und Berücksichtigung der maßgeblichen öffentlichen und privaten Belange verpflichtet, nicht die Beklagten (wird ausgeführt).

cc. Die Schaffung einer modernen und funktionsfähigen Verkehrsinfrastruktur ist demgegenüber eine originäre Pflicht der Beklagten. §§ 3, 4 AEG verpflichten die Beklagten dahingehend, dass die Eisenbahn nebst den dazugehörigen Anlagen dem öffentlichen Verkehr dient. Sie sind verpflichtet, ihren Betrieb sicher zu führen, die Bahn und die Eisenbahninfrastruktur sicher zu bauen und in einem betriebssicheren Zustand zu erhalten - dazu gehört auch eine Modernisierung. Danach sind die Beklagten verpflichtet, die notwendigen Maßnahmen zu ergreifen, die zu einer modernen, sicheren und ausreichend dimensionierten Verkehrsinfrastruktur gehören.

\section{Pflicht zur Prüfung von weniger einschneidenden Planungsvarianten}

Eine Pflicht zur Prüfung von weniger einschneidenden Planungsvarianten besteht entgegen der Auffassung des Klägers nicht. Im Rahmen der Interessenabwägung ist nur die von den Beklagten konkret gewählte Planung zu bewerten. Es kommt also nicht darauf an, ob andere Wettbewerbsvorschläge den Erhalt der Flügelbauten vorgesehen haben oder ob eine Umplanung technisch möglich ist und welchen Aufwand diese erfordert. Der Eigentümer definiert, welche Planungsvariante in die Abwägung einzustellen ist.

Zwar muss der Eigentümer eines urheberrechtlich geschützten Bauwerks bei Abänderungen grundsätzlich eine den betroffenen Urheber in seinen urheberpersönlichkeitsrechtlichen Interessen möglichst wenig berührende Lösung suchen. Wenn der Eigentümer sich aber für eine bestimmte Lösung entschieden hat, geht es bei der Interessenabwägung nur noch darum, ob dem Urheber die geplanten konkreten Änderungen des Bauwerks zumutbar sind. Ob daneben noch andere, den Urheber gegebenenfalls weniger beeinträchtigende Lösungen denkbar sind, ist hierfür nicht mehr von entscheidender Be- 
deutung (BGH GRUR 2008, 984 [988 Rn. 39] - St. Gottfried; BGH GRUR 1974, 675 [678] - Schulerweiterung; ablehnend Bielenberg GRUR 1974, 678 f., der ausführt, es sei dem Eigentümer zuzumuten, die schonendere Lösung zu wählen oder auf den Eingriff zu verzichten). Für die Richtigkeit dieser Auffassung spricht die Überlegung, dass es nicht die Aufgabe des Gerichts sein kann, verschiedene Planungsvarianten zu bewerten und damit an die Stelle des Vorhabenträgers zu treten.

Danach ist für die Interessenabwägung die konkret geplante Änderung des Bauwerks zugrunde zu legen, andere Lösungen bleiben außer Betracht. Soweit der Kläger hier aus dem Begriff „zumutbar" („[...] ob die geplanten konkreten Änderungen des Bauwerks zumutbar sind [...]") etwas anderes herleiten will, wird damit nur umschrieben, dass die Interessenabwägung zugunsten oder zuungunsten des Urhebers ausgehen kann, letzteres, wenn die Änderung zumutbar und deshalb hinzunehmen ist.

\section{Abschwächung der Urheberrechte durch Zeitab- lauf als Kriterium für die Interessenabwägung}

Im Gegensatz zur Auffassung des Klägers geht der Senat davon aus, dass bei der Interessenabwägung eine Abschwächung der Urheberrechte durch Zeitablauf angenommen werden kann.

Soweit dem in der Literatur (und vom Kläger) entgegengehalten wird, dies widerspreche der monistischen Konzeption des Urheberrechts als einheitliches, materielle und ideelle Interessen vereinendes Recht und der klaren Regelung zur Schutzdauer (Schulze in: Dreier/Schulze, UrhG, 3. Aufl. 2008, § 12 Rn. 8; Bullinger in: Wandtke/Bullinger, Praxiskommentar zum Urheberrecht, 3. Aufl. 2009, vor § 12 ff. Rn. 10; Obergfell GRURPrax 2010, 233 [236]), kann dem der Senat nicht folgen. Es handelt sich insoweit um einen allgemeinen Rechtsgrundsatz, wobei der BGH zutreffend auf die Parallele zum allgemeinen Persönlichkeitsrecht hinweist. Dies zeigt beispielsweise aber auch das Institut der Verwirkung. Es liegt auf der Hand, dass ein Recht im Laufe der Zeit Veränderungen unterworfen sein kann. Das landgerichtliche Urteil hat in diesem Zusammenhang zutreffend darauf hingewiesen, dass die angeordnete Schutzdauer nicht bedeutet, dass keine Abwägung erfolgen darf. Die Schutzfrist des § 64 UrhG wird hierdurch auch nicht in Frage gestellt oder entwertet, es geht vielmehr um die Intensität des Urheberpersönlichkeitsrechts im Rahmen der vorzunehmenden Interessenabwägung.

\section{Beeinträchtigung des Werks, Gefährdung der berechtigten Urheberinteressen}

Die geplanten Arbeiten tangieren die Substanz des Bauwerks und bewirken eine erhebliche Veränderung des ästhetischen Gesamteindrucks, die die berechtigten Urheberinteressen gefährden.

\section{Zur Abwägung der gegenläufigen In- teressen}

Trotz der erheblichen Schöpfungshöhe und des überragenden Rangs des Werkes, weshalb grundsätzlich ein hohes Erhaltungsinteresse des Urhebers besteht, und trotz des erheblichen Eingriffs in das Gesamtbauwerk überwiegen die Eigentümerinteressen der Beklagten. Das Bestands- und Integritätsinteresse des Urhebers Paul Bonatz tritt hinter dem Veränderungsinteresse der Beklagten zurück. Maßgeblich und wesentlich ist insoweit, dass nach der vorliegenden Planung die berechtigten Modernisierungsinteressen der Beklagten bei dem Bahnhof als Zweckund Verkehrsbau - Änderung des Kopfbahnhofs in einen Durchgangsbahnhof - nur mit einem Abriss der Seitenflügel und einer Veränderung der Treppenanlage in der großen Schalterhalle erreicht werden können, da der Durchgangsbahnhof die Seitenflügel durchsticht und die Treppenanlage nicht mehr als Zugang zu den Bahngleisen dienen kann. Für die konkret geplante Ausführung ist der Abriss zwingend erforderlich, um einen Durchgangsbahnhof schaffen zu können. Dabei ist auch zu berücksichtigen, dass die Urheberinteressen angesichts der verbleibenden Schutzdauer von 16 Jahren erheblich an Gewicht verloren haben und dass die Beklagten mit dem Umbau des Bahnhofs ihrer öffentlichen Pflicht genügen, der Allgemeinheit eine moderne Verkehrsinfrastruktur zur Verfügung zu stellen.

Die geltend gemachten städtebaulichen Belange sind für die vorzunehmende Interessenabwägung demgegenüber nicht relevant.

\section{Vertraglich eingeräumte Änderungsrechte oder Verwertungszwecke}

Die Beklagten können sich allerdings nicht auf (ausdrücklich oder konkludent) eingeräumte vertragliche Änderungsrechte berufen, sie machen dies letzten Endes auch nicht geltend. In der Sache wird lediglich vorgetragen, der Architektenvertrag ergebe, dass schon dem eigentlichen Urheber Bonatz klar war, dass es zu Änderungen kommen kann, er selbst habe beim Wiederaufbau nach der Zerstörung und der Anbringung des Sterns auf dem Turm eine pragmatische Haltung eingenommen (...). Der Kläger hat eingeräumt, dass sein Großvater offen für Änderungen gewesen sei, er wäre aber sicher nicht mit der geplanten „Entstellung und Verstümmelung“ einverstanden gewesen (...).

Ausweislich $\S 5$ des Architektenvertrages vom 14./30. Mai 1913 - weitere Regelungen zu Änderungen des Bauwerks enthält der Vertrag nicht - hatten sich die Architekten verpflichtet, Umarbeiten der Pläne bei notwendigen Änderungen des Bauwerks „im Laufe der Bauzeit" ohne eine besondere Vergütung zu übernehmen (...). Schon nach dem klaren Wortlaut der Vereinbarung sind lediglich Änderungen während der Bauzeit geregelt worden. Zudem ist diese Vereinbarung als eine Ausnahme von der Regel eng auszulegen, denn das Urheberrecht geht als Regel von einem grundsätzlichen Änderungsverbot aus, das nur ausnahmsweise durchbrochen werden darf (s.o. unter V. 1.). 
Da der Wegfall der Seitenflügel und die Abänderung der Treppenanlage weitreichende Eingriffe in den ursprünglichen Bestand des Gesamtbauwerks enthalten und keine Feststellungen mehr möglich sind, inwieweit Paul Bonatz tatsächlich mit solchen Änderungen einverstanden gewesen wäre (er empfand unstreitig schon den Mercedesstern als „dégoutant"), eine Entscheidung könnte insoweit lediglich auf Mutmaßungen beruhen, kann die Beklagte daraus keine Recht herleiten.

Vertraglich eingeräumte Änderungsrechte oder ein unspezifisches Einverständnis können deshalb im Rahmen der Interessenabwägung nicht berücksichtigt werden. Unabhängig davon ist aber festzuhalten, dass sich die Parteien darüber einig sind, dass Paul Bonatz gegenüber Änderungen grundsätzlich offen war (Streit besteht nur über die Reichweite seiner Änderungstoleranz).

\section{Individueller Schöpfungsgrad, überragende Schöpfungshöhe}

Bei dem Bahnhofsgebäude handelt es sich um ein Werk der Baukunst mit einer hohen schöpferischen Qualität, der Kläger beruft sich deshalb zutreffend auf ein hohes Erhaltungsinteresse. Der Senat hat bereits festgestellt (s.o. unter IV. 2.), dass es sich bei dem gesamten Bahnhofsgebäude um ein außergewöhnliches Werk der Baukunst handelt, das weit über das durchschnittliche Architektenkönnen hinausgeht und eine überragende Schöpfungshöhe aufweist. Es handelt sich um einen wichtigen Großbau der Architektur des beginnenden 20. Jahrhunderts, der Urheber Paul Bonatz („,wichtigste Bauaufgabe meines Lebens"; [...]) und die Fachwelt schätzen den Bahnhof als dessen Hauptwerk ein. In einem Zeitungsartikel der Süddeutschen Zeitung vom 26. November 2009 (...) wird aus einem Schreiben des Internationalen Rats für Denkmalpflege (Beratergremium der Unesco bezüglich der Welterbeliste) zitiert, wonach der Bahnhof zu den vier wichtigsten Bahnhofsgebäuden Europas gehöre.

Im Rahmen der Interessenabwägung ist deshalb von einem hoch zu bewertenden Erhaltungsinteresse auszugehen.

Soweit der Kläger in diesem Zusammenhang auch auf architekturgeschichtliche sowie denkmalschutzrechtliche Belange verweist und auf die zentrale städtebauliche Bedeutung des Gesamtgebäudes abstellt (...), haben die Beklagten zutreffend darauf hingewiesen, dass städtebauliche und kulturpolitische Belange nicht berücksichtigt werden können, da im Rahmen der Abwägung lediglich die urheberrechtspersönlichen Belange maßgeblich sind. Denn die Beurteilung der Werkqualität und die Interessenabwägung sind durch das jeweilige Gericht vorzunehmen (s.o. V. 2. c. und die dortigen Nachweise).

\section{Art und Ausmaß des Eingriffs}

Bei den geplanten (und begonnenen) Baumaßnahmen handelt es sich um wesentliche Änderungen mit erheblichen Auswirkungen auf die Gesamtwirkung des Bauwerks.

a. Der Abriss der Seitenflügel und der Wegfall der Treppe bewirken schwerwiegende und endgültige Eingriffe in die Integrität des Gesamtgebäudes. Dessen Gesamteindruck, der ja gerade auch durch die Kombination der verschiedenen kubischen Formen mit unterschiedlichen Größen charakterisiert wird (s.o. IV. 2.), geht unwiederbringlich verloren. Die einrahmende und abgrenzende Funktion der Flügel entfällt und ist zukünftig nicht mehr wahrnehmbar. Dies gilt auch für die Treppenanlage der großen Schalterhalle.

b. Soweit die Parteien darüber streiten, ob dennoch im Rahmen der Interessenabwägung berücksichtigt werden kann, dass Teile des Bauwerks erhalten werden, ist dieser Streit nicht zielführend.

aa. Der Kläger führt insoweit aus, das Bauwerk werde zum Torso amputiert und verstümmelt, das Gebäude unersetzbar beschädigt (Blatt 40, 194 der Akten). Der Gesamteindruck des Werkes lebe von der Komposition der einzelnen Bauelemente, die jeweils unterschiedliche Volumina aufweisen, sich aber zu einem großen Ganzen zusammenfügen (...). Die Seitenflügel seien Integrationsklammern und vermittelten dem Bau Stabilität und Dichte (...), der Gesamteindruck werde durch den Abbruch zerstört (...); der Bahnhof sei eine architektonische Gesamtheit und könne nicht in einen Hauptteil und Seitenflügel zerlegt werden (...), die Seitenflügel hätten nicht nur eine funktionale Bedeutung als Einfassung des Gleisbettes, sondern auch die Funktion der Abtrennung von Schlossgarten (Südflügel) und als Anschluss zur Kopfseite der Kopfbahnsteighalle (Nordflügel) (...), sie seien integrale Bestandteile der städtebaulich eingebundenen Architektur (...).

Die Beklagten halten dem entgegen, der architektonisch wichtigste Teil des Bonatz-Baus bleibe erhalten (...), die Änderung des Kopfbahnhofs in einen Durchgangsbahnhof führe zu einem Verlust des funktionalen Bezugs und der Bedeutung der Seitenflügel (...) - die Seitenflügel müssten als Folge der funktionalen Änderung des Kopfbahnhofs in einen Durchgangsbahnhof weichen (...).

bb. Es trifft zwar zu, dass Art und Ausmaß eines Eingriffs auch objektiv gemessen werden können, indem die wegfallenden und die bestehen bleibenden Bauvolumina gemessen werden (ein wesentlicher Eingriff würde dann Volumenbeeinträchtigungen von jedenfalls mehr als $50 \%$ erfordern), damit wird aber das maßgebliche Ziel einer Abwägung der verschiedenen Interessen verfehlt. Denn es geht bei der Frage nach Art und Ausmaß des Eingriffs um Wertungskriterien, was sich schon allein daraus ergibt, dass die Rechtsprechung auf eine Veränderung der Ge- 
samtwirkung, auf den künstlerischen Gesamteindruck und die diesen prägenden schutzfähigen Gestaltungselemente, also auf wertende Begriffe abstellt, die Spielräume zulassen.

Der Vorwurf der Berufung, das Urteil des Landgerichts enthalte insoweit widersprüchliche Feststellungen, ist deshalb nicht nachvollziehbar. Es ist nach den gemachten Ausführungen durchaus zulässig, nach einem festgestellten schweren Eingriff die damit zusammenhängende Frage der Eingriffsintensität zu erörtern und diese in die Interessenabwägung einzustellen.

cc. Trotz des Abrisses von erheblichen Teilen des Gesamtgebäudes bleiben auch wesentliche und architektonisch bedeutende Teile des Bauwerks erhalten. Denn der Bahnhof wird nicht nur durch die Seitenflügel, sondern vor allem auch durch die Bahnsteighallen und den großen Turm charakterisiert.

Insoweit ist auch zu berücksichtigen, dass die Veränderung des Konzepts vom Kopfbahnhof zum Durchgangsbahnhof jedenfalls die Funktion der Flügelbauten als Abgrenzungsbau zu den Gleisanlagen entbehrlich macht.

\section{Abschwächung der Urheberinteressen wegen Ablaufs der Schutzdauer}

Das infolge der hohen schöpferischen Qualität und des Umfangs des Eingriffs anzunehmende hohe Erhaltungsinteresse wird durch eine Abschwächung der Urheberinteressen relativiert, denn nach einem Ablauf von mehr als $3 / 4$ der Schutzdauer (54 von 70 Jahren) hat das Erhaltungsinteresse nicht mehr dasselbe Gewicht wie noch zu Lebzeiten des Architekten Paul Bonatz. Soweit der Kläger die Auffassung vertritt, eine Abschwächung komme generell nicht in Betracht, wird auf die obigen Ausführungen unter VI. 3. Bezug genommen.

a. Der Urheberschutz endet wegen § 64 UrhG siebzig Jahre nach dem Tod des Urhebers Bonatz (dieser verstarb am 20. Dezember 1956), also am 31. Dezember 2026, da es sich um eine Jahresfrist handelt ( $\$ 69$ UrhG). Wegen $\S 129$ UrhG gilt auch insoweit der seit 1965 auf 70 Jahre verlängerte Urheberschutz (vergleiche nur Dreier in: Dreier/Schulze, UrhG, 3. Aufl. 2008, vor $\S \S 64$ ff. Rn. 9 und $\S 64$ Rn. 5).

b. Unabhängig von der sicherlich hohen Bedeutung des Bahnhofs für seinen Urheber Paul Bonatz - er schrieb in einem Brief vom 19. Juni 1949 anlässlich des Wiederaufbaus, für ihn handle es sich um die wichtigste Bauaufgabe seines Lebens (...), und schilderte den Bau des Bahnhofs als das wichtigste Kapitel für seine Entwicklung als Baumeister (...) - sowie unabhängig von der Erhaltung der Erinnerung durch die bloße Präsenz des imposanten Gebäudes, welches auch als Bonatz-Bau bezeichnet wird, führt die Tatsache, dass der Tod des Urhebers nunmehr 54 Jahre zurückliegt, zu einer Abschwächung und Relativierung der Urheberrechte. Denn im Laufe eines so langen Zeitraums tritt die Verbindung eines Gebäudes mit seinem geistigen Schöpfer naturgemäß immer mehr in den Hintergrund. Im
Rahmen der Interessenabwägung haben die Erhaltungsinteressen des Urhebers nicht mehr notwendig dasselbe Gewicht wie zu seinen Lebzeiten, zumal angesichts des Alters des Gebäudes auch Modernisierungs- und Veränderungsinteressen bestehen können.

\section{Gebrauchszweck und bestimmungsgemäße Ver- wendung - Notwendigkeit von Veränderungen}

a. Da es sich bei dem Bahnhofsgebäude um einen Zweckbau handelt, denn er soll in erster Linie seinen Nutzern als Verkehrsbauwerk dienen (und ist erst in zweiter Linie Kunstwerk), die Beklagten insoweit berechtigte Modernisierungsinteressen sowie veränderte Nutzungsbedürfnisse geltend machen können und der Abriss der Flügel und der Treppenanlage für die geplante Veränderung erforderlich (notwendig) ist, treten im Rahmen der Interessenabwägung die durch den Zeitablauf relativierten Urheberinteressen hinter den Eigentümerinteressen der Beklagten zurück. Der Bahnhof ist anders als ein Gemälde oder eine Skulptur nicht nur nach rein künstlerischen Ideen gestaltet (auch wenn er als Ganzes ein Kunstwerk ist), seine Gestaltung folgt vielmehr auch technischen und funktionalen Anforderungen. Dieser Zweck begründet die Notwendigkeit der geplanten baulichen Veränderungen.

b. Der Vortrag des Klägers, technisch sei die Erhaltung der Flügelbauten trotz der geplanten Änderung in einen Durchgangsbahnhof ohne weiteres möglich (...), ist unbeachtlich, denn der Kläger hat eingeräumt, dass eine Erhaltung der Flügelbauten erhebliche Umplanungen erfordern würde und der planfestgestellte Entwurf nicht in dieser Form realisiert werden könnte. Im Termin vor dem Senat hat der Kläger wörtlich ausgeführt, es sei richtig, dass der Ingenhoven-Entwurf nicht eins zu eins umgesetzt werden kann, wenn man die Flügelbauten erhält. Der Kläger führt weiter aus, dass die Statik des Dachs die Flügelbauten nicht tragen könnte und diese durchstochen werden. Nach bisheriger Planung sind deshalb die Seitenflügel unstreitig zu beseitigen. Im Rahmen der Interessenabwägung ist aber nur die geplante konkrete Änderung zu bewerten, es kommt also nicht darauf an, ob es weniger einschneidende Alternativen gibt (s. o. VI. 2.).

aa. Der Kläger hat auf den Vortrag der Beklagten, die Veränderungen seien erforderlich, um das Gebäude den Gegebenheiten des neuen Durchgangsbahnhofs anzupassen (...), das Dach des Tiefbahnhoftroges, die fragile Deckenkonstruktion mit den Lichtaugen könne die Flügelbauten statisch nicht tragen (...), ausgeführt, technisch sei die Erhaltung der Flügelbauten ohne weiteres möglich (...), es bestehe keine zwingende Notwendigkeit, wegen Stuttgart 21 die Flügelbauten abzureißen (...). Der Kläger zieht insoweit auch aus den Abläufen der Ausschreibung und der Vergabe den Schluss, dass es nur um ein städtebauliches Immobilienprojekt, um städtebauliche Belange gehe (...). 
bb. Demgegenüber hat der Kläger aber schon im Anhörungsverfahren und auch in öffentlichen Äußerungen eingeräumt, dass die Konzeption der vorliegenden Planung die Erhaltung der Flügelbauten nicht erlaube (...). Er trägt im Prozess selbst vor, dass der Durchgangsbahnhof die Flügelbauten unterfährt beziehungsweise durchsticht (...), und hat die Richtigkeit der von den Beklagten vorgelegten Computeranimation nicht in Abrede gestellt (deren Richtigkeit ist also gemäß § 138 Abs. 3 ZPO unstreitig), wonach die Decken der Bahnhofshalle bis über das Erdgeschoss der Flügel hinausgehen und die Züge nicht unter den Flügelbauten hindurch kommen würden (...). Auch der dazugehörige Sachvortrag des Hineinragens der Fundamente und der unteren Geschosse der Seitenflügel in die neue Bahnhofshalle (...) ist nicht bestritten, dies ergibt sich sogar positiv aus der vom Kläger vorgelegten Anlage K 8 (...). Der Kläger trägt in diesem Zusammenhang auch vor, dass eine Abfangung und punktuelle Lastabtragung der Flügelbauten erforderlich wäre (...), also (erhebliche) Umplanungen und Veränderungen der gewählten Lösung erforderlich wären. Er räumt ein, dass das Dach des vorgesehenen Bahnhofs (statisch) nicht ausreicht, um die Belastungen der Flügelbauten aufzunehmen (...). In einem Interview und einem Modifizierungsvorschlag hat der Kläger dazu ausgeführt, dass die Erhaltung der Seitenflügel eine Verringerung der Höhe der Bahnhofshalle voraussetzen würde (...).

cc. Die Unvereinbarkeit der Planungen mit den vorhandenen Seitenflügeln ergibt sich aus den folgenden Animationen, die von den Beklagten als Anlage B 23 vorgelegt wurden.

dd. Dass die Änderung der im Original nicht mehr vorhandenen Treppenanlage notwendig ist, ergibt sich ebenfalls aus der geänderten Funktion des Bahnhofs. Denn die Treppe kann durch die tiefer gelegten Bahngleise nicht mehr ihre Funktion als Zugang zu den Bahngleisen erfüllen, was sich ohne weiteres aus der von den Beklagten vorgelegten Visualisierung ergibt (...). Der Kläger stellt dies nicht in Abrede, denn er trägt selbst vor, dass der Zugang zu den Bahnsteigen über die Treppe wegen der tiefer gelegten Gleise nicht mehr nötig ist (...). Zudem ist der Abriss der Treppe funktional erforderlich, um den nach dem Umbau zu erwartenden Personenströmen zur künftigen Bahnhofshalle gerecht zu werden (...).

\section{ee. Danach steht für den Senat fest, dass}

- für eine Erhaltung der Flügelbauten und der Treppenanlage erhebliche Änderungen der Planungen erforderlich wären,

- die Dachkonstruktion des Tiefbahnhofs die Seitenflügel statisch nicht tragen kann,

- die Seitenflügel in den neuen Tiefbahnhof hineinragen, diesen durchstechen, weshalb die Flügelbauten einer Änderung des Gebrauchszwecks entgegenstehen,
- die bisherige Funktion der Treppenanlage als Zugang zu den Gleisen entfällt.

Entgegen der Auffassung des Klägers und einer Äußerung in der Literatur (Obergfell GRURPrax 2010, 233 [235]) ist danach der Abriss der Seitenflügel notwendig und erforderlich. Davon ist ersichtlich auch das Landgericht ausgegangen (...). Der klägerische Vorwurf von fehlenden oder unzureichenden Feststellungen ist deshalb nicht nachvollziehbar.

c. Im Rahmen der Interessenabwägung ist maßgeblich zugunsten der Beklagten zu berücksichtigen, dass der veränderte Gebrauchszweck - Änderung des Durchgangsbahnhofs in einen Tiefbahnhof aufgrund geänderter Verkehrsbedürfnisse und eines berechtigten Interesses zur Modernisierung des ca. 90 Jahre alten Bahnhofs - in Verbindung mit der Notwendigkeit der Veränderungen wegen der entschiedenen Planungsvariante und der Tatsache, dass es sich bei einem Bahnhof in erster Linie um einen Zweckbau handelt, eine Veränderung erforderlich machen.

In diesem Zusammenhang ist auch zu berücksichtigen, dass der funktionale Zweck der Seitenflügel (zumindest teilweise) entfallen wird. Die Seitenflügel haben beim Stuttgarter Hauptbahnhof neben dem Zweck einer Abgrenzung zum Schlossgarten hin (Südflügel) und des Anschlusses zur Kopfseite der Kopfbahnsteighalle hin (Nordflügel), so auch der Klägervortrag[...]), weiter die Funktion einer Einfassung der Gleise des Kopfbahnhofs. Funktion und Bedeutung lassen sich instruktiv den vorgelegten Luftbildern (...) entnehmen. Der Kläger hat selbst in einem Presseinterview die Seitenflügel als sich zum Empfang der Züge öffnende Arme gesprochen (...). Die Einfassungs- und Abgrenzungsfunktion entfallen aber durch den Wegfall des Kopfbahnhofs. Die tiefer gelegten Gleise und der neue Tiefbahnhof müssen nicht mehr umfasst werden.

Die Seitenflügel und die Treppenanlage sind für das neue Bahnhofskonzept nicht mehr erforderlich, sie stehen diesem sogar im Weg. Gerade bei einem Zweckbau sind aber auch bei hoher Schutzwürdigkeit die Eigentümerinteressen vorrangig.

\section{Modernisierungsinteressen}

Das Bestehen eines Modernisierungs- und Veränderungsinteresses hat der Kläger ausdrücklich zugestanden, denn er trägt vor, die Klage richte sich nicht gegen die Umwandlung in einen Durchgangsbahnhof (...), er streite nicht gegen das Projekt Stuttgart 21 (...). Der Vortrag der Beklagten, dass der ca. 90 Jahre alte Bahnhof als Zweckbau weiterentwickelt werden müsse, es bestehe im Hinblick auf geänderte Anforderungen der Verkehrsinfrastruktur und geänderte Verkehrsbedingungen ein Modernisierungsinteresse (...), der bestehende Kopfbahnhof könne das vorgesehene Betriebskonzept nicht bewältigen (...), ist ebenfalls nicht bestritten worden, also gemäß § 138 Abs. 3 ZPO zugestanden. Die Beklagten haben vorgetragen, es gehe um die Bereitstellung einer langfristig leistungsfähigen Schie- 
neninfrastruktur, die Einbindung der Neubaustrecke und des Bahnknotens in das europäische Hochgeschwindigkeitsnetz, eine Erhöhung der Streckenleistungsfähigkeit, die Verbesserung der Verkehrsanbindung. Diese Ziele, deren Definition Sache der Beklagten ist, erfordern einen Durchgangsbahnhof, an den das Gebäude angepasst werden muss. Die Bahnhofsanlage soll auch aus Gründen des Lärmschutzes unterirdisch errichtet werden (...). In seiner Replik auf die Berufungserwiderung führt der Kläger dazu aus, er führe keinen Kampf gegen das Bahnprojekt Stuttgart 21, keinen Kampf gegen die Umwandlung des Kopf- in einen Durchgangsbahnhof und keinen Kampf gegen die Integration des Bahnhofs in das neue Schieneninfrastrukturkonzept. Die von den Beklagten geltend gemachten Modernisierungsinteressen hinsichtlich des Bahnhofsgebäudes sind damit eingeräumt worden und können deshalb bei der Interessenabwägung zugunsten der Beklagten berücksichtigt werden.

Soweit der Kläger aus den Abläufen schlussfolgernd vorträgt, im Vordergrund stünden andere - städtebauliche - Motive, es gehe tatsächlich um ein Immobilienprojekt (die Beklagten tragen vor, dass diverse Ziele verfolgt werden), machen die Beklagten jedenfalls auch berechtigte Modernisierungsinteressen geltend. Das Urheberrecht darf insoweit aber nicht dazu führen, dass Bauwerke von der technischen Weiterentwicklung gänzlich ausgeschlossen werden (ebenso Goldmann GRUR 2005, 639 [643]).

\section{Wirtschaftliche Gesichtspunkte}

Der Kläger hat ausdrücklich eingeräumt, dass bei einem Erhalt der Seitenflügel und der Treppenanlage erhebliche Umplanungen erforderlich sind, ist aber der Meinung, hierdurch werde das Gesamtprojekt billiger (...). Ungeachtet der Tatsache, dass Änderungen bei derartigen Großprojekten erfahrungsgemäß nahezu immer mit erheblichen Mehrkosten verbunden sind (die Beklagten sprechen pauschal von mehreren 100 Mio. EUR; [...]), steht angesichts der Ausführungen unter 6. fest, dass der Vorschlag des Klägers nicht realisierbar ist, weil die Dachkonstruktion des Tiefbahnhofs die Seitenflügel nicht trägt. Letzten Endes kommt es darauf aber nicht an, denn in die Interessenabwägung ist nur die konkret geplante und ausgewählte Variante einzustellen (s.o. Vl. 2.) - auf die Kosten einer Umplanung kommt es deshalb nicht an.

\section{Allgemeininteressen und öffentliche Interessen - hier: städtebauliche Belange}

Die geltend gemachten städtebaulichen Belange sind aus Rechtsgründen nicht in die Abwägung einzustellen (s.o. VI. 1.). Ferner sind sie aus tatsächlichen Gründen nicht relevant.

Die von den Beklagten geltend gemachten öffentlichen Interessen betreffen nicht den Abriss der Seitenflügel und die Umgestaltung der Treppenanlage. Die Seitenflügel und die Treppe müssen nicht für die geplante städtebauliche Entwicklung abgerissen werden, die Entwicklung soll vielmehr ganz überwiegend auf den dahinter liegenden freiwerdenden Gleisflächen erfolgen, betrifft also nicht den eigentlichen Umbau des Bahnhofs. Soweit der Wegfall der Seitenflügel erfolgt, weil auf diesem Gelände Parkflächen entstehen sollen, kann dies vernachlässigt werden. Die Flügel betreffen offensichtlich einen unerheblichen Teil der freiwerdenden Flächen (...). Ein irgendwie gearteter städtebaulicher Gewinn bezüglich des Abbruchs der Seitenflügel ist danach nicht erkennbar. Hinsichtlich der Treppenanlage ist dies erst recht nicht nachvollziehbar. Diese liegt im Inneren des Gebäudes und tangiert deshalb keine städtebaulichen Belange.

\section{Allgemeininteressen und öffentliche Interessen - hier: Schaffung einer modernen Verkehrsinfra- struktur}

Insoweit wird auf die Ausführungen unter 6. zu den Modernisierungsinteressen Bezug genommen, es handelt sich in der Sache um die gleichen Interessen.

\section{Gesamtabwägung - Zusammenfassung}

Zusammenfassend ist nochmals festzuhalten, dass wegen der hohen Schöpfungshöhe und des überragenden Rangs des Werkes grundsätzlich ein hohes Erhaltungsinteresse des Urhebers besteht und von einem erheblichen Eingriff in das Gesamtbauwerk auszugehen ist. Dennoch überwiegen im vorliegenden Sachverhalt die Eigentümerinteressen der Beklagten. Das Bestands- und Integritätsinteresse des Urhebers Bonatz tritt deshalb hinter dem Veränderungsinteresse der Beklagten zurück. Maßgeblich und wesentlich ist insoweit, dass die Modernisierungsinteressen der Beklagten bei dem Bahnhof als Zweck- und Verkehrsbau - Änderung des Kopfbahnhofs in einen Durchgangsbahnhof - nach der vorliegenden Planung nur mit einem Abriss der Seitenflügel und einer Veränderung der Treppenanlage in der großen Schalterhalle erreicht werden können, da der Durchgangsbahnhof die Seitenflügel durchsticht und die Treppenanlage nicht mehr als Zugang zu den Bahngleisen dienen kann. Der Abriss ist daher zwingend erforderlich, um diesen Durchgangsbahnhof schaffen zu können. Dabei ist auch zu berücksichtigen, dass die Urheberinteressen angesichts der verbleibenden Schutzdauer von 16 Jahren erheblich an Gewicht verloren haben und dass die Beklagten mit dem Umbau des Bahnhofs ihrer öffentlichen Pflicht genügen, der Allgemeinheit eine moderne Verkehrsinfrastruktur zur Verfügung zu stellen.

Die geltend gemachten städtebaulichen Belange sind für die vorzunehmende Interessenabwägung demgegenüber nicht, jedenfalls nicht in entscheidungserheblichem Umfang, relevant.

\section{Nebenentscheidungen}

I. Die Nebenentscheidungen beruhen auf $\S \S 91,97,709,711$ ZPO. 
II. Gründe für eine Zulassung der Revision sind nicht ersichtlich. Es handelt sich zwar um einen Sachverhalt, der angesichts der Diskussion um das Projekt eine sehr breite Öffentlichkeitswirkung entfaltet, die maßgeblichen rechtlichen Probleme sind aber höchstrichterlich geklärt. Grundsätzliche Bedeutung hat eine Rechtssache nur dann, wenn sie eine klärungsbedürftige und klärungsfähige Rechtsfrage aufwirft, die sich in einer unbestimmten Vielzahl weiterer Fälle stellen kann (BGHZ 159, 135 [137]; $B G H Z$ 151, 221 [223]). Klärungsbedürftig ist eine Rechtsfrage, wenn ihre Beantwortung zweifelhaft ist oder wenn zu ihr unterschiedliche Auffassungen vertreten werden und die Frage höchstrichterlich noch nicht geklärt ist (BGHZ 159, 135 [138]). Das ist nicht der Fall.

III. Für die Streitwertfestsetzung sind folgende Überlegungen maßgeblich:

1. Dem Kläger geht es um den Erhalt des Werks aus ideellen Belangen (Hartmann Kostengesetze, 38. Aufl. 2008, § 48 GKG Rn. 12 unter dem Stichwort Urheberrecht). Sein Interesse an der Unterlassung ist unter Berücksichtigung aller Umstände des Falles zu bewerten. Angesichts der vom Kläger geschilderten hohen Bedeutung des Werks und seinem großen Interesse besteht kein Anlass, hinsichtlich des gestellten ursprünglichen Unterlassungsantrags von der Streitwertangabe der Klageschrift abzuweichen.

2. Mit dem geänderten Antrag auf Wiederaufbau des Nordflügels macht der Kläger insoweit einen vermögensrechtlichen Schadenersatzanspruch oder Beseitigungsanspruch geltend. $\S 48$ Abs. 2 GKG ist insoweit ebenfalls anzuwenden, denn es geht weiter um den ererbten urheberrechtlichen Anspruch, der nicht auf einen vermögenswerten Vorteil gerichtet ist.

a. Für die Abgrenzung zwischen vermögensrechtlichen und nichtvermögensrechtlichen Streitigkeiten kommt es auf die Rechtsnatur des Anspruchs an, den der Kläger geltend macht, allein maßgeblich ist der Vortrag des Klägers (Schneider/Herget Streitwertkommentar, 12. Aufl. 2007, Rn. 4156; Hartmann Kostengesetze, 38. Aufl. 2008, § 48 GKG Rn. 4). Insoweit ist einhellig anerkannt, dass zu den vermögensrechtlichen Ansprüchen auch Ansprüche aus nichtvermögensrechtlichen Verhältnissen gehören, soweit sie eine vermögenswerte Leistung zum Gegenstand haben (BGH JZ 1982, 512; RGZ 144, 158 [159]; Hillach/Rohs Handbuch des Streitwerts in Zivilsachen, 9. Aufl. 1994, § 9 A. I. a), S. 38). Nichtvermögensrechtliche Streitigkeiten sind solche, die nicht auf Geld oder Geldeswert gerichtet sind und nicht aus vermögensrechtlichen Verhältnissen entspringen. Vermögensrechtliche Streitigkeiten sind solche, bei denen die Ansprüche auf Geld oder eine geldwerte Leistung gerichtet sind, gleichgültig, ob sie aus einem vermögensrechtlichen oder nichtvermögensrechtlichen Grundverhältnis entspringen (Schneider/ Herget Streitwertkommentar, 12. Aufl. 2007, Rn. 4157; Madert/ von Seltmann Gegenstandswert in bürgerlichen Rechtsangele- genheiten, 5. Aufl. 2008, Rn. 355). Vermögensrechtlich sind auch Ansprüche, die auf vermögensrechtlichen Beziehungen beruhen (BGHZ 83, 106 [109]).

b. Inhalt und Umfang des Ersatzes materieller Schäden bestimmen sich auch im Urheberrecht grundsätzlich nach den allgemeinen Vorschriften der §§ 249 ff. BGB (BT-Drucks. IV/270 zu $\S 107$ UrhG in der Fassung 1965, heute $\S 97$ UrhG). Soweit eine Verletzung der Urheberrechte wieder rückgängig gemacht werden kann, ist insoweit auch eine Naturalrestitution in der Form der Wiederherstellung des Zustands denkbar, der bestehen würde, wenn die Rechtsverletzung nicht stattgefunden hätte (Nordemann in: Fromm/Nordemann, Urheberrecht, 10. Aufl. 2008, § 97 Rn. 68; Dreier in: Dreier/Schulze, UrhG, 3. Aufl. 2008, $\S 97 \mathrm{Rn} .58$ geht davon aus, dies sei regelmäßig nicht der Fall).

Der Anspruch ergibt sich insoweit nicht schon aus $\S 97$ Abs. 1 Satz 1 UrhG in der Form der dort definierten Beseitigung der Beeinträchtigung, denn der Anspruch auf Wiederherstellung des ursprünglichen Zustands ist ein Schadenersatzanspruch aus $\S 249$ BGB (Nordemann in: Fromm/Nordemann, Urheberrecht, 10. Aufl. 2008, §97 Rn. 60), es geht nicht nur um die Beseitigung der Beeinträchtigung für die Zukunft (vergleiche nur Palandt/ Bassenge BGB, 69. Aufl. 2010, § 1004 Rn. 28).

c. Der geltend gemachte Anspruch auf Wiederaufbau beruht weiter auf Urheberpersönlichkeitsrechten (also immateriellen, nicht vermögensrechtlichen Ansprüchen) und ist nicht auf eine berechenbare geldwerte Leistung gerichtet. Der Wiederaufbau würde beim Kläger nicht zu einem in Geldwert messbaren Vermögenszuwachs führen, denn er wird nicht Eigentümer des Bahnhofs. Bei ihm bleibt es unverändert der immaterielle (nicht vermögensrechtliche) Anspruch aus dem Urheberrecht, der Abriss hat sein Interesse nicht verändert. Der Kläger macht insoweit auch keinen (in Geld berechenbaren) Vermögensschaden geltend.

Selbst wenn man mit der Entscheidung des Reichsgerichts in RGZ 97, 397 („Felseneiland auf Sirenen“) annehmen wollte, dass insoweit ein Beseitigungsanspruch besteht, wäre auch insoweit nicht von einer geldwerten Leistung auszugehen.

Es bleibt daher beim ursprünglichen Streitwert. (Entscheidung von der Redaktion bearbeitet.) 